CDD. 407

\title{
A profissão "professor" como atividade feminina nas capas da revista nova escola: discursos e representação
}

\section{Teaching as a feminine profession in the covers of the magazine nova escola: discourse and representation}

Eliana Cristina Pereira Santos ${ }^{*}$

\begin{abstract}
Resumo: As escolas do Ensino Fundamental do Paraná apresentam quantidade significativa de professoras em comparação ao número de docentes do gênero masculino. Por sua vez, observa-se também nas capas da revista Nova Escola uma alta predominância da representação feminina em relação à profissão de "professor". Interessam, pois, a este trabalho os vários discursos veiculados a respeito da representação da profissão docente. O corpus analisado engloba capas com imagens e ilustrações que evidenciam a representação da docência como sendo profissão predominantemente feminina. Abordam-se discursos e representação imagética do feminino que corroboram para produzir e reproduzir demarcações e estereótipos distintivos do gênero feminino. A proposta é descrever que formas de feminilidade são reforçadas, polemizadas, imaginadas, na colaboração da construção cultural. Analisam-se representações que reforçam e contribuem para manutenção da identidade feminina na docência, especialmente nos anos iniciais escolar. Procura-se uma possibilidade de se atribuir novos olhares às respectivas imagens veiculadas pela mídia impressa.

Palavras-chave: Discursos. Mídia. Feminino e representação.

Abstract: There is a significant number of female teachers compared to the number of male teachers in elementary schools in Paraná. It is also observed a predominance of feminine representation of the profession in the covers of Nova Escola Magazine. This paper discusses the numerous discourses related to the representation of the teaching profession. The corpus analyzed includes magazine covers that show images and illustrations demonstrating that the teaching profession is predominantly feminine. The article also presents discourses and representations of the feminine imaginary that corroborate the production and reproduction of feminine stereotypes. The article intends to describe which forms of femininity are reinforced, problematized and imagined in the cultural construction. The representations that reinforce and contribute to the maintenance of a feminine identity in teaching, especially in the early years of schooling, are analyzed. The article also tries to attribute new forms of understanding the imagines present in the written media.
\end{abstract}

Keywords: Discourse. Media. Feminine and representation.

Eliana Cristina Pereira Santos, mestranda em Letras. Universidade do Oeste do Paraná- UNIOESTE - eliana.lee@ig.com.br 
Eliana Cristina Pereira Santos

\section{Introdução}

Estudos revelam que durante a década de 50, no século XX, surgiram vários movimentos sociais. As mulheres, principalmente as casadas, organizaram-se, formando o movimento liberal de luta das mulheres conhecido como feminismo. Buscavam igualdade de direitos civis, políticos e educativos, direitos que eram destinados apenas aos homens. Na França, as mulheres lutavam pela necessidade de serem valorizadas as diferenças entre homens e mulheres, especialmente no que dizia respeito à experiência feminina. Já nos Estados Unidos, as feministas salientavam a denúncia da opressão masculina e a busca de igualdade. Uma luta contra a discriminação do sexo feminino e pela garantia de direitos, principalmente do direito ao voto e ao mercado de trabalho, no qual começaram a conquistar o seu espaço. Iniciaram um processo diaspórico do espaço privado - cozinhas e alcovas - e migraram, embora ainda que timidamente, para o espaço público, para o trabalho fora de suas casas.

Segundo Costa e Silveira (1998), a imprensa feminina passa a orientar as escolhas ditas "profissionais", mas com argumentos de que a função primordial da mulher na sociedade é garantir a tranquilidade da família e de que o futuro da raça humana dependeria de sua atuação como mãe e protetora do reduto familiar. Então, para as mulheres foram sugeridas as seguintes profissões: enfermeira e professora, "profissões do cuidado", como se cuidar de alguém fosse a única tarefa aceitável e característica da mulher - exercendo o que seria sua "vocação maternal". Ou seja: ser enfermeira requeria uma atitude terna, carinhosa, de dedicação e, por conseguinte, características presentes na figura da mulher que, pelo seu "instinto maternal", já traria consigo tais atributos. Além disso, ser professora pressupunha uma atitude de cuidado com a formação das crianças e dos jovens, preparando-os para a vida; requeria carinho, paciência, perseverança e abnegação; novamente características fortemente atribuídas às mulheres.

Diante deste breve retrospecto histórico e tendo por referência a revista Nova Escola, a segunda mais vendida depois da Veja, no Brasil, procuramos, com este artigo, tecer considerações relevantes sobre as representações da profissão de professor; sobre as relações simbólicas desta cultura que nos auxilia na definição de homem ou mulher, ou seja, toda a carga simbólica adquirida culturalmente, que estabelece identidade do gênero masculino ou feminino. Em outras palavras, procuramos analisar como os discursos veiculados pela capa 
A profissão professor como atividade feminina nas capas da Revista N ova Escola: discursos ...

da mencionada revista apresentam a representação do professor, considerando a relevância que é dada ao gênero feminino. Buscamos uma possibilidade não de interpretação, mas de novos olhares para a mídia.

\section{Identidade e representação do sujeito professor}

Sob o olhar sociológico, buscamos em três autores definições sobre a formação da identidade. Em Hall (2005), encontramos as múltiplas identidades do sujeito, que sofrem deslocamentos constantes, numa busca incessante no processo de construção de identificação. Segundo Foucault (2002), a identidade: são "vários eus" simultâneos e várias posições desse sujeito. E, finalmente, em Baumam (2005) encontramos a discussão da identidade como flutuantes. Portanto, no que concerne a esses autores, cabe dizer que as identidades dos sujeitos estão relacionadas também com seus papéis sociais.

No que tange ao corpus deste trabalho, estamos tratando de representação do sujeito professor. Sujeito entendido como alguém que, através de sua função social, afirma sua identidade como ato de afirmação político, assume uma posição social que lhe garanta acesso aos direitos e deveres enquanto profissional, no caso, professor. No caso feminino, com a identidade de professora, porém, sem negar outras funções sociais: mãe, mulher, dona de casa, profissional, tia, filha esposa, etc. Essas representações que corroboram para o processo de identificação dos sujeitos são sistematizadas pela sociedade, com lógica própria compartilhada pela coletividade no nível social e simbólico, ou seja, elas são constituídas por símbolos e imagens que, segundo Laplantine e Trindade (1990), é uma maneira, encontrada pelas pessoas, de conhecer, perceber e interpretar e representar a sua realidade, atribuindo-lhe significados.

Nesta perspectiva, as capas da revista Nova Escola são manifestações culturais, são representações do real, impregnadas de símbolos. Símbolos que são ações intencionais produzidas nas interações da pessoa com a situação social, no interior dos discursos. Cada capa representa símbolos e imagens, ou seja, um conjunto de significados elaborados para compreender a realidade. Nas palavras de Bourdieu (1990), os discursos enquanto símbolos têm o poder quase mágico de imposição. Além de compreender a realidade por meio desses símbolos, os sujeitos são impregnados pelos mesmos símbolos que, de maneira mágica, impõem modelos, atitudes, comportamentos. 
Sobre representação, valemo-nos de Goffman (2005) que utiliza a metáfora do teatro. Em A representação do eu na vida cotidiana $\mathrm{o}$ autor explica que o eu, sujeito, atua projetando seus personagens em outros personagens, seus papéis sociais projetados por outros "eus", várias identidades que são, também, a plateia. A plateia, termo teatral, é, na vida cotidiana, vivida pelos que assistem ao desempenho do eu, sujeito. O simples fato de representar denota que os indivíduos são atores, encenam em diferentes palcos e para diversas plateias. Como atores, os sujeitos assumem diferentes papéis, escondem ou revelam segredos, criam impressões altamente simbólicas, pois cuidadosamente estão veiculando discursos e transmitindo uma visão que julgam ser aceitável ao outro. Então, para este autor estamos sempre representando, independente da identidade construída.

Sendo assim, as capas, selecionadas para este estudo contêm imagens dessas representações de professoras em figuras ilustrativas. Essas figuras são signos imagéticos que estão em constante tentativa de contato, todo o tempo querem - mesmo que inconscientemente - manter um elo em sua comunicação com o leitor, com a plateia, com o outro. Segundo Goffman (2005), a tentativa constante deste elo seria colocar suas faces e tentar esconder suas contra-faces; representar um papel escondendo o outro. E, através da expressão e representação de diferentes papéis, o sujeito pode conhecer aos outros e a si mesmo, já que ao apresentar-se diante dos outros, seu desempenho tenderá a incorporar os valores oficialmente reconhecidos pela sociedade, ao mesmo tempo em que estará influenciando outros, ou seja, nas práticas da representação o sujeito está intrinsecamente ligado às partilhas culturais.

\section{A profissão professor}

Segundo Nóvoa (1991) a docência, ao longo dos séculos, foi se delineando e se estruturando como profissão, na medida em que ia sendo definido a quem competia a função de educar. Por volta do século XVI, essa atribuição estava a cargo da Igreja, cabia a algumas congregações religiosas a responsabilidade específica da educação formal, prova disso são alguns colégios particulares não laicos que ainda restaram em quase todas as cidades do Brasil. Somente em meados do século XVII é que, em processo gradativo, os docentes foram sendo transformados em funcionários públicos, ou seja, o 
A profissão professor como atividade feminina nas capas da Revista N ova Escola: discursos ...

Estado assumiu a educação. Essas diversas mudanças na atividade docente acarretaram a criação de associações profissionais, conforme a afirmação do autor, que:

a emergência deste ator corporativo constitui a última etapa do processo de profissionalização da atividade docente, na medida em que corresponde à tomada de consciência do corpo docente de seus próprios interesses enquanto grupo profissional. (NÓVOA, 1991, p. 125).

É neste contexto que o autor, em seus estudos sobre a profissão-professor, destaca o processo de obtenção de uma identidade profissional. A identidade do professor, segundo ele, foi construída por meio de criação de associações, da organização enquanto grupo com ideias e valores sobre a profissionalização docente. Entretanto, esse é só um item entre outros que, historicamente, dão base para debates e discussões sobre questões educacionais e sobre as relações entre educação e sociedade, e professor na sociedade.

Deste modo, é importante compreender como a constituição das representações identitárias dessas professoras se compõem. Reitera-se que, segundo Hall (2000), as identidades são produzidas no interior de formações discursivas, revelando muito pouco as razões pelas quais os indivíduos ocupam determinadas "posições-de-sujeito" e não outras.

Nesse sentido, a construção identitária do professor ou professora, representada nessas iconografias das capas, resulta das inscrições sociais de uma sociedade marcada pela historicidade referente às conquistas do feminino sobre o masculino, o machismo, o patriarcalismo, por sistemas classificatórios (masculino/feminino) resultantes das relações de poder. Devemos ressaltar que, embora as identidades sejam marcadas por intensa mudança, ao pensar enquanto possibilidade de conquista de espaço e equiparidade salarial, é provável que permaneçam as mesmas. Ainda segundo Hall (2000), encontramos no processo de formação da identidade fundamentação histórica, linguística e cultural em função da produção, não daquilo que nós somos, porém daquilo no qual nós nos tornamos, ou seja, a constituição de cada professor, como se tornou professor. Nesse caso, pode-se perceber que essas identidades são historicamente marcadas por um contexto impregnado pela herança machista, em que as mulheres eram somente mães e, portanto deveriam ser administradoras de seus lares.

Sob esta perspectiva ressalta-se que este artefato representa a síntese de pensamentos sociais e, colocados nas capas, representam as múltiplas formas

Uniletras, Ponta Grossa, v. 32, n. 1, p. 77-90, jan./ jun. 2010 
de entender e de assumir lugares e posturas sociais femininas na profissão professor. Essas capas trazem experiências, valores, posturas profissionais e pessoais, formas de pensar e agir, que deveriam ser discutidos, nos processos de formação inicial e continuada, buscando a re(construção) das imagens da/na docência que nos produzem professores. Trazer essas representações como materiais para as discussões nos cursos de formação possibilita a des(construção) da atuação do professor a partir de seus referenciais de docência.

Necessário lembrar a afirmação de Foucault de que onde há poder há resistência, mas que este mesmo poder não é centralizado, é multifacetado e age em instâncias diferenciadas. As capas, faces de moedas de consumo, propõem imagens fragmentadas de professores e comportamentos.

Mas onde estarão situadas as marcas da resistência das professoras leitoras, que leram nestas capas um concurso para o professor nota 10, e como desenvolver um trabalho em equipe, ou ainda como alfabetizar uma turma, sem falar, sobre o cuidar da aparência, o que vestir, aonde ir, como falar, como se apresentar como educadora? Somente a continuidade da pesquisa poderá mostrá-la. Na legitimação da docência como profissão eminentemente feminina, além da mídia, as instituições da sociedade têm papel importante. Principalmente a família, a escola e a igreja, que muitas vezes limitam a escolha da mulher, impondo forçosamente a opção pela carreira docente.

\section{Capas em análise}

Publicações especificamente destinadas a professores, como a Nova Escola, e convênios entre revistas e escolas compõem uma tradição bem sucedida de parceria entre a mídia impressa e a educação. Porém, a pretensa homogeneidade do discurso midiático sobre o professor nos intriga, uma vez que o discurso é constatado na heterogeneidade. Numa sociedade capitalista como esta em que vivemos, vale expor imagens, capas, espaços de discursos já veiculados. São espaços que representam discursos, saberes resistências, religiosidade, conformismo. Nesta re-visitação evocamos seis capas "antigas". 
A profissão professor como atividade feminina nas capas da Revista N ova Escola: discursos ...

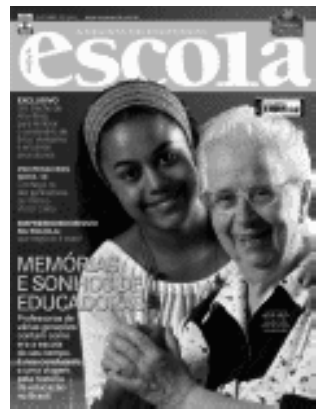

Capa 1 Revista Nova Escola ed 186,outubro/2005e

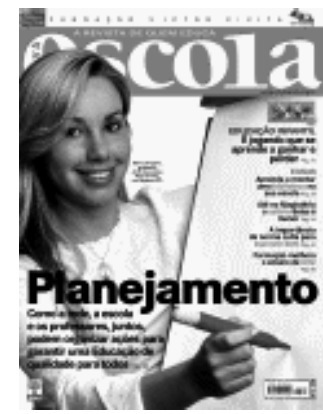

Capa 2 Revista Nova Escola, d.198,dezembro/2006

No plano imagético da capa 1, os sujeitos representados e as identidades (re) construídas são recuperados no processo dialógico da significação, no entrecruzamento das formações discursivas envolvidas com a história das posições de sujeito que estão sendo representadas. Assim, verificamos uma figura jovem e uma senhora. Revelam, pelo lugar, indícios de representação de uma identidade coletiva em que a professora, sempre centralizada nas capas, está em evidência. Portanto, na arqueologia dos processos de produção de identidade e de representação de sujeitos, depreende-se dos tex tos imagéticos estudados que são discursivisadas as posições de mulher-mãe e de mulher-professora. Esta revista, veiculada nas escolas, reproduz a lógica com que são "feitos" os professores. Como podemos perceber, a representação de uma professora idosa e de uma professora jovem, na mesma capa, dois momentos históricos, sedimentando um eixo central do imaginário coletivo em relação à identidade de professoras mulheres. Assim, olhar a senhora idosa é uma forma de ver nela a recorrência, aspectos históricos e femininos de uma professora. Ver atualizadas na jovem o papel professora, eterniza o papel de professor representado em nossa sociedade, isto é, um ciclo de outros discursos (re) apresentados, um tempo cíclico. Esta temporalidade é um princípio importante para entender como um discurso é sedimentado. A profissão professor (re)aparece nova na forma ou no discurso, uma comparação atenta permite perceber uma impressionante semelhança no plano estrutural: olhar carinhoso, roupas recatadas, ambas são mulheres. Indícios de que ali opera uma temporalidade religiosa, não linear, cíclica, que aposta na permanência e que está fora do eixo histórico. A dicotomia como são apresentados esses aspectos é que nos impressiona: diferentes tempos cronológicos, nova/idosa; negra/branca; 
iniciante/aposentada, cabelo curto/comprido. Lado a lado, a imagem da professora jovem simboliza a nova geração; ao lado, a segunda professora encara a câmera fotográfica com um sorriso, como de quem já trilhou um caminho na educação e está feliz, realizada. Ela encara o/a leitor/a como uma mulher que está ali, de cabeça erguida defendendo um ideal que não tem preço, é uma doação às crianças. A imagem das duas professoras faz uma linha de tempo da profissão, seguimento da carreira de educadora. É interessante observar o olhar da senhora, ele permite que os leitores olhem para foto e imaginem $o$ quanto foi maravilhosa a vida daquela senhora em sala de aula.

Considerando a capa 2, podemos afirmar que vários fatores contribuíram para produzir certas imagens da mulher em nossa sociedade e, consequentemente, essas imagens se estabilizam e sedimentam os discursos, que culminam em estereótipos. Um deles se fundamenta no discurso machista: mulher como objeto de desejo. A professora representada na capa 2 tem as seguintes características: loura, magra, branca, bem vestida, dentes perfeitos, cabelos longos. Esse sentido aparece como fato da ordem da normalidade, de forma que essa capa acaba por trazer à tona sentidos preconceituosos em relação à aparência de outras professoras que não são jovens, loiras, de pele branca, cabelos longos e unhas bem feitas. Sobre o que se refere à forma de se maquiar, vestir-se, a aparência é domesticada; a ela se empregam técnicas e estratégias para que esteja cada vez mais próximo ao ideal do belo consumível. Desejar estar bem apresentável, vestir determinada roupa ou acessório, estar em forma (ser magra) são retratos do consumo em que desejos se transformam em atos socialmente regulados. O consumo torna-se cada vez mais próximo de um pacto de identificação e colaboração: a revista mostra 0 que um professor pode ser. O professor, que consome, identifica-se com os modelos expostos e tenta parecer-se, sempre mais, com o que a revista mostra. Com este movimento, a professora garante legitimidade às imagens das capas e aos enunciados oferecidos a cada número. Consumir as capas, seus modelos e discursos é uma tentativa de diferenciação e distinção social, com seus aspectos simbólicos e estéticos. 
A profissão professor como atividade feminina nas capas da Revista N ova Escola: discursos ...

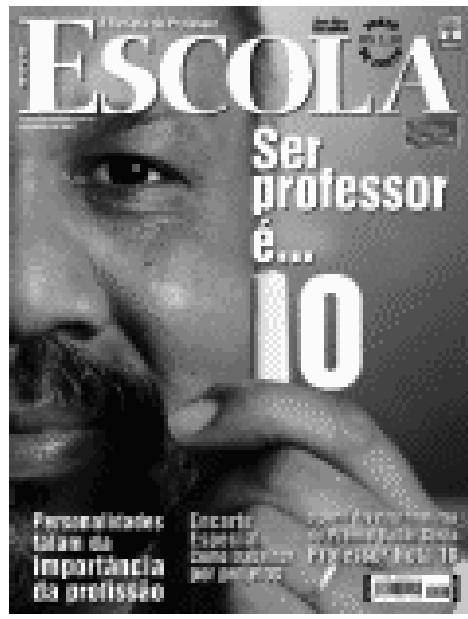

Capa 3 Revista Nova Escola, ed.146 outubro/2001

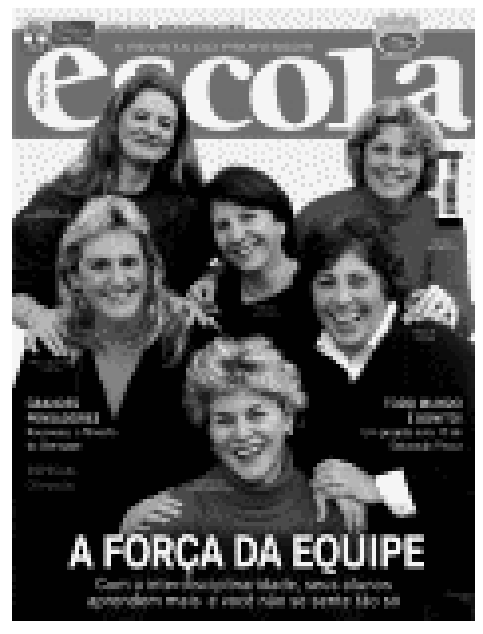

Capa 4 Revista Nova Escola, ed.174 agosto/2005

Observando estas capas, entende-se que analisar a representação do feminino implica também olhar para as representações do gênero masculino, uma vez que, historicamente, o gênero feminino e o masculino foram representados de forma dicotômica, frequentemente em oposição. Se não considerarmos as condições de produção em que essa capa foi feita, é possível empreender outra leitura e compreender que o gênero masculino bem como o negro aparecem também representados nas capas. Entretanto, essa capa foi produzida em outubro, mês em que se comemora o Dia do Professor, no ano de 2001.

Apesar de o maior contingente de pessoas que segue a carreira do magistério ser constituído de mulheres, comemoramos no dia 15 de outubro o Dia do Professor e não o Dia da Professora. A capa, ao mesmo tempo em que retoma na memória a lembrança da comemoração, faz um jogo de publicidade, veiculando o projeto: Professor nota 10, concurso realizado anualmente, criado pela própria revista para premiar um único professor, como o melhor daquele ano. Contudo nas escolas são realizados projetos, muitos desenvolvidos em sala de aula, então como, competitivamente, escolher "o melhor"?

Contradizendo o projeto de ter um único professor excelente, a capa número 4 representa A FORÇA DA EQUIPE. Não uma, mas seis professoras, alegres sorridentes, e em posição muito amigável, modelos de trabalho 
em equipe. Vê-se o cuidado com a aparência, nas vestes, nos acessórios e no cabelo; a elegância das roupas. De um modo geral, ao homem são permitidas determinadas posturas e atitudes muito mais flexíveis e livres em relação aos padrões que são impostos às mulheres, das quais se exige postura, maquiagem, elegâncias irretocáveis, em que impera a elegância e o zelo no que tange a diversos aspectos da sua vida. Todas essas marcas são bem visíveis nas capas, as quais, através das representações, trazem e reforçam os paradigmas condizentes com a nossa sociedade.

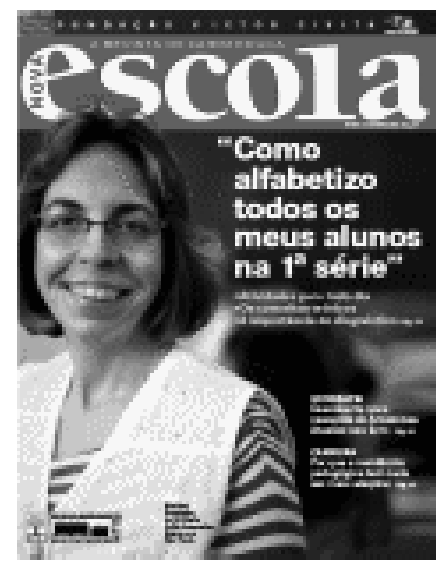

Capa 5 Revista Nova Escola ed.201 abril/2007

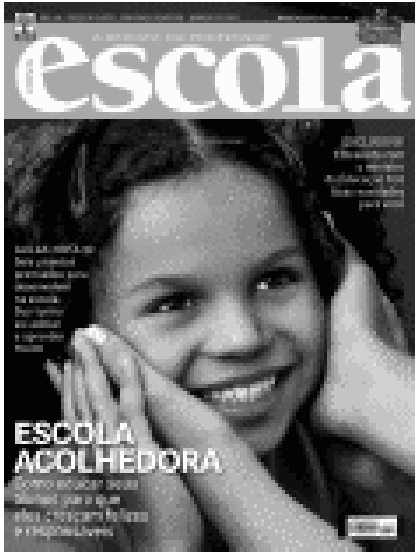

Capa 6 Revista Nova Escola, ed. 188 março/2007

Parece que, com o passar dos anos, a editoração da revista começou a se preocupar com a representação veiculada pelas suas capas. Desde então, começou a fazer inúmeras mudanças na sua apresentação. Por exemplo, a capa 5 , produzida em 2007, destoa das demais. Percebemos a imagem de professor mais próximo da realidade, principalmente se compararmos com a capa 2. Denota, ainda, uma preocupação de estar representando toda uma classe de professores, ao querer ser mais realista, e a imagem parece ser realmente uma professora no exercício de sua função. A imagem segue o modelo foto-ilustrativo publicitário, no qual o personagem se deixa fotografar fazendo pose para câmera. Apesar de desfocado, o fundo da imagem indica que a fotografia não foi produzida em estúdio, apresenta uma coloração verde, intercalada por pontos muito claros de luz. Como boa apresentadora, a personagem olha a objetiva e esboça um tímido sorriso para buscar a intimidade com os leitores 
A profissão professor como atividade feminina nas capas da Revista Nova Escola: discursos ...

da revista. $\mathrm{O}$ espaço retratado simboliza uma sala de aula. Procura um efeito maior de verdade, inclusive, utiliza como enunciado uma fala da professora. $\mathrm{O}$ enunciado apresentado entre aspas justifica tratar-se de uma fala. $\mathrm{O}$ uso dos pronomes EU e MEUS acoplados ao verbo conjugado na primeira pessoa do singular ALFABETIZO. Esta professora está autorizada a falar, ela é uma profissional, que está dentro da sala de aula. Para os leitores quem está falando não são autoridades, mas a própria professora falando sobre a sua experiência. Além disso, percebe-se a exploração de um efeito visual através da fotografia desta reportagem.

Já na capa 6 destacamos uma outra cisão: a das profissões "ideais" para mulheres: inspira proteção e carinho maternal. Metaforicamente pelas mãos de uma mulher, reveladas pela pintura das unhas, um gesto carinhoso envolve o rosto de uma criança sorridente. $\mathrm{O}$ sentido fica mais claro acoplado ao enunciado ESCOLA ACOLHEDORA. O léxico enunciativo também merece a nossa atenção, já que completa sentidos para as imagens e, funcionando de modo articulado, "conduzem" o olhar, o que colabora para a produção de determinados significados. Esta capa parece sustentada por um não-dito, que através da imagem é rememorado: carinho no crescimento da criança é coisa de mulher, a ela cabe cuidar educar os filhos, ou seja, o olhar dócil da criança dá sentido de proteção, de amparo, ao mesmo tempo que reafirma o vínculo entre educação e infância. Representa a professora como mulher-heroína da educação, que orienta e defende alunas/os que se sentem felizes e protegidos na escola.

No discurso da mídia, temos a multiplicação de uma imagem padrão da "boa escola" ou da "boa educação", escola acolhedora. A capa evidencia a defesa de um discurso, da valorização excessiva da afetividade na profissão docente. Em um estudo sobre a ação da mídia no campo da educação construindo a identidade feminina na profissão docente, Costa e Silveira (1998) observa que:

palavras e imagens [...] formam um conjunto de perspectivas, métodos e verdades, organizados e colocados à disposição, constituindo práticas com propriedades prescritivas, moldadoras e fixadoras. (COSTA E SILVEIRA, 1998, p. 349).

Sendo assim, a revista Nova Escola corrobora com ideias, afirmando e reafirmando as distinções entre os papéis femininos e masculinos. Essa divisão ainda continua nítida, a moral sexual diferenciada permanece forte, e o 
trabalho da mulher no magistério, ainda que cada vez mais comum, cercado de micro preconceitos, é visto como subsidiário ao trabalho do homem, a pessoa "que educa".

\section{Considerações finais}

Diante de uma sociedade que se moderniza no aspecto econômico, podemos perceber a relutância face à probabilidade de mudanças no terreno dos costumes, pois ainda são as mulheres as responsáveis pela higiene da casa, educação e cuidado com os filhos, preparo dos alimentos. Elas devem estar sempre perfumadas, magras, unhas feitas, roupas na moda e impecáveis. Mesmo já estando estabelecido socialmente um discurso moral, uma ditadura da moda sobre os trajes da professora, alguns modelos não são aceitos: decotes, saias/vestidos acima do joelho, acessórios grandes que se sobressaem, maquiagens fortes e vibrantes, penteados. São aceitos os modelos de mulher prendada e nascida para casar. Então, a mulher deste século vive um sério conflito: ser bonita, interessante e atraente e, ao mesmo tempo, extremamente discreta e recatada. A aparição das mulheres nas capas da revista Nova Escola na profissão de professor é um fato. Afinal é a revista de quem educa.

Entretanto, é possível perceber que existem mudanças significativas, se compararmos com as capas de revistas de décadas anteriores, onde figuravam mulheres como simples objeto decorativo e, quase sempre, não dispunham de temas que focassem suas preocupações, problemas e aspirações.

As identidades, tanto do homem quanto da mulher, se traduzem na mídia pelos seus aspectos relacionais, gramaticais, como códigos ou padrões nos quais a sociedade cruza ideias, estilos, práticas e nelas aloja os atores sociais. As identidades neste sentido não são dimensões do indivíduo, pairando além do social, pois transformadas em imagens da mídia, sua instância decisória não é mais o foro íntimo.

As professoras representadas são criadas para serem desejadas, reproduzem formas de pensar e agir em relação à profissão, bem como a sua forma de utilização, seu desempenho, sua concretude, sua individualização e padronização. Quem compra a revista, compra a representação, o comportamento e as relações de poder que ela está apresentando. As capas são metáforas do rótulo e da superfície/superficialidade proposta às professoras, mostram-nos 
A profissão professor como atividade feminina nas capas da Revista Nova Escola: discursos ...

condições de existência da nossa cultura midiática em relação ao ser professor, a identidade de educador. Não são imposições, mas resultados de relações de poder baseadas na cooperação por uma representação do gênero feminino, bem como pelos comportamentos reconfigurados.

Como foi demonstrado ao longo deste texto, as capas são marcadas por uma circularidade, uma repetição exaustiva de algumas representações femininas, que podem ser entendidas como parte de uma estratégia que busca fixar determinados sentidos, tornando-os referências de normalidade. Este investimento em torno dos significados e lugares sociais femininos mostra, como observa Hall (1997), que não existem significados finais, naturais ou definitivamente fixados, mas sim embates, jogos de força e lutas no campo das representações. Este estudo, portanto, deve ser visto como um exercício sobre algo pontual, um balão de ensaio ou uma interpretação plausível de um caso concreto de construção da identidade de professor como sendo preferencialmente uma profissão feminina.

\section{Referências}

BAUMAN, Z. Identidade. Trad. Carlos Alberto Medeiros. Rio de Janeiro: Jorge Zahar, 2005

COSTA, M. V.; SILVEIRA, R. M. H. A revista Nova Escola e a constituição de identidades femininas. In: BRUSCHINI, Cristina; HOLANDA Heloísa Buarque de (Orgs.). Horizontes plurais: novos estudos de gênero no Brasil. São Paulo: Ed. 34, 1998. p.343-78

FISCHER, R. M. B. Mídia e educação da mulher: uma discussão teórica sobre modos de enunciar o feminino na TV. Rev. Estud. Fem., 2001, v.9, n.2, p.586-599.

Adolescência em discurso: mídia e produção de subjetividade. Porto Alegre: UFRGS/FACED/PPGEDU, 1996. (Tese, Doutorado em Educação).

FOUCAULT, M. A arqueologia do saber. Rio de Janeiro: Forense 2002.

GOFFMAN, Erving. A representação do eu na vida cotidiana. 13. ed. Petrópolis: Vozes. 2005.

HALL, Stuart. A centralidade da cultura: notas sobre as revoluções de nosso tempo.

Educação \& Realidade. Porto Alegre: 1997.

A identidade cultural na pós-modernidade. Trad.: TOMAZ, Tadeu da

Silva; GUACIRA, Lopes Louro. Rio de Janeiro: DP\&A, 2005.

LAPLANTINE, François; TRINDADE, Liana. O que imaginário. São Paulo: Brasiliense, 1997.

Uniletras, Ponta Grossa, v. 32, n. 1, p. 77-90, jan./jun. 2010 
NÓVOA, Antônio. Para o estudo sócio-histórico da gênese e desenvolvimento da profissão docente. Revista Teoria \& Educação - Dossiê Interpretando o trabalho docente, Porto Alegre: Editora Pannonica, n. 4, 1991.

A formação profissional dos professores. In: NÓVOA, A. (Org.). Profissão professor. 2. ed. Porto/Portugal: Porto Editora, 1995.

REVISTA NOVA ESCOLA A força da equipe. Disponível em: <http://revistaescola.abril. com.br/edicoes/indice_anteriores_2005.shtml>. Acesso em: 10 jul. 2007.

“Como alfabetizo todos os meus alunos na $1^{a}$ Série". Disponível em: <http:// revistaescola.abril.com.br/edicoes/indice_anteriores_2007.shtml> Acesso em: 10 jul. 2007.

Escola acolhedora. Disponível em:

<http://revistaescola.abril.com.br/ed_anteriores/0180.shtml>. Acesso em: 10 jul. 2007.

Memórias e sonhos de educadoras. Disponível em: <http://revistaescola.abril. com.br/edicoes/indice_anteriores_2005.shtml> Acesso em: 10 jul. 2007.

.Planejamento. Disponível em: $<$ http://revistaescola.abril.com.br/edicoes/indice_anteriores_2006.shtml>. Acesso em: 10 de jul. 2007.

Ser professor é 10. Disponível em: <http://revistaescola.abril.com.br/edicoes/ indice_anteriores_2001.shtml> Acesso em: 10 de jul. 2007.

Recebido para publicação em 21 jun. 2010. Aceito para publicação em: 14 jul. 2010. 